

\title{
MACROMOLECULES, ACTUALLY: FROM PLASTICS TO DNA
}

\section{Alexander B. Cook ${ }^{1 *}$ and Lucka Bibic ${ }^{2 *}$}

${ }^{1}$ Laboratory of Nanotechnology for Precision Medicine, Italian Institute of Technology, Genoa, Italy

${ }^{2}$ School of Pharmacy, University of East Anglia, Norwich, United Kingdom

\section{YOUNG REVIEWERS:}



ANJISHNU

AGE: 12

JEANINE

AGE: 15
"I feel it in my fingers, I feel it in my toes, the love that is all around me." These might be the words of a popular Christmas song from the movie Love Actually, but this could just as easily be a song about macromolecules-large molecules all around us. From your nails and hair to the rubber tips on your earphones, they are everywhere. You are made of macromolecules and so are trees and plastic water bottles! We call them polymers-long stretches of identical molecules with a range of useful properties, like toughness or stretchiness. And, it turns out, we just cannot live without them. Polymers occur both naturally-the DNA in our cells is a polymer-and synthetically (man-made), like plastic, Silly Putty and Styrofoam. This article uncovers the mysteries of polymers and explains how these fascinating materials have shaped life as we know it. 
Figure 1

In the world of macromolecules, polymers are large-chain molecules made from repeating units of smaller molecules that are called monomers (shown on the left). In Greek, "poly" means many, and "mer" means part. While homopolymers are formed from a single type of monomer (blue dots), copolymers and precision polymers contain more than one monomer (blue and green dots). Precision polymers have a precise sequence that gives the polymer a specific structure (blue, green, and orange dots).

\section{MACROMOLECULE}

A very large molecule that contains thousands of atoms or more.

\section{POLYMER}

A large molecule, or macromolecule, composed of many repeating units called monomers.

\section{MONOMER}

A building block, or repeating unit, of a polymer.

\section{SYNTHETIC}

Man-made from chemicals.

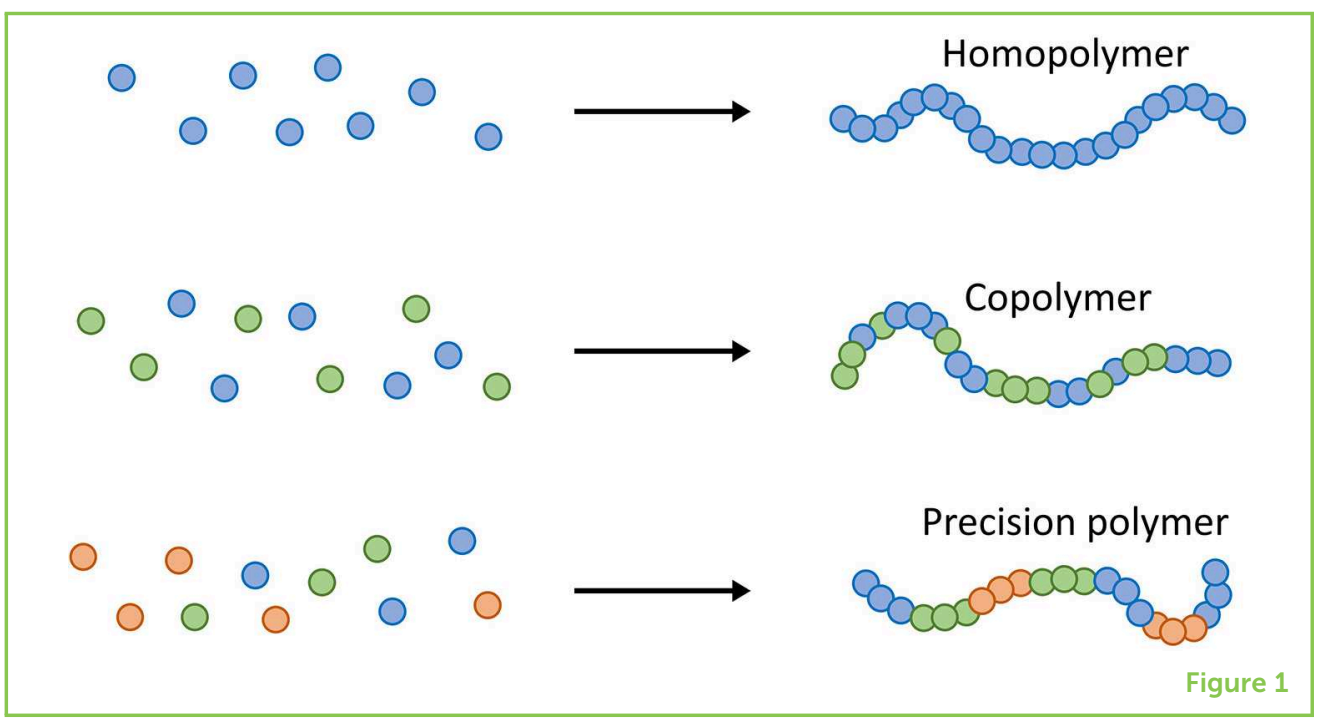

\section{MACROMOLECULAR MATERIALS—BUILDING BLOCKS OF LIFE}

The scientific word for a very large molecule is macromolecule, because "macro" means large. Polymers are macromolecular materials that touch almost every aspect of our lives. Chances are most of us have been in contact with at least one polymer-containing product-from water bottles to gadgets to tires-in the last $5 \mathrm{~min}$. In fact, the term polymer itself gives us a clue about how these materials are designed. In Greek, "poly" means many, and "mer" means part. To better picture this, imagine you are making a necklace out of beads. Each bead represents an atom. You could string together single beads in a row. Or, you could make clusters of one type of bead with other ones, and then string those together. In a polymer, the individual beads are called monomers. Once put together, the monomers make up the polymer. Figure 1 shows a simplified diagram of how monomers build different types of polymers.

To better understand polymers, we must examine each type of monomer they are made from. Polymers come in different shapes and sizes, and they are either man-made or naturally occurring in plants or animals. For example, proteins are one type of polymer and they are made from monomers called amino acids. Depending on which amino acids and how many of them bond together, the resulting protein could be found in hair or nails, muscles, skin, or important cell machinery. Another naturally occurring polymer is starch, which serves as the food storage for plants like potatoes, corn, and wheat. Starch is a tasty polymer that can be found in bread and pasta! For the past 150 years, humans have been learning how to make synthetic (or man-made) polymers. Today, we can play with natural polymers like cellulose-a polymer made out of glucose (a form of sugar)-or human-made polymers like Teflon, which is derived from petroleum oil. 


\section{THE STORY OF MACROMOLECULES}

Although polymers may be as old as life itself, we have only known about them since the 1830s when scientists first described them. The first synthetic polymer, known as Bakelite, which was the first plastic, was made in 1907 by an easy and inexpensive reaction. Later, Bakelite helped engineers to manufacture many types of children's toys and kitchenware. But it was not until the 1920s when Herman Staudinger, a German scientist who worked on these synthetic polymers, coined the term macromolecule. Unfortunately, many scientists did not believe him about the existence of macromolecules because, at the time, a lot of chemists were reluctant to admit the existence of "giant organic molecules." Rather, they preferred the idea that many natural substances-such as cellulose, silk, and rubber-consisted of small units held together by exceptionally strong forces. After Staudinger announced the concept of macromolecules, one well-known chemist even said, "you might as well claim that somewhere in Africa one elephant was found who was 1,500 feet long and 300 feet high" [1, 2]. Funnily enough, while the elephant did not exist, the polymer did, and the discovery of polymers revolutionized science.

It was not until the 1940-50s when researchers discovered that some polymers existed naturally in the human body, including proteins, which we already described as polymers of amino acid monomers, and DNA. DNA is made of monomers called nucleotides. When scientists built the first model of the natural polymer DNA, they realized that the structure of the DNA molecule helped to explain the way DNA functions to code for all the information needed to create the organism.

\section{THE STRUCTURE OF MACROMOLECULES}

As time went on, scientists continued to study the structure of macromolecules. They found that natural polymers are often much smaller than their longer synthetic versions. They also discovered that the length of these synthetic polymers, and the patterns in which the monomers are arranged, are what makes synthetic polymers strong, lightweight, transparent, and flexible. But polymers also have another superpower-they have many different shapes! In Figure 2A, you can see three main shapes of polymers: linear, branched, and cross-linked. Long, linear polymers look like cooked spaghetti. Unlike branched polymers, linear polymers are likely to get tangled up and become sticky and elastic. On the other hand, cross-linked polymers have lots of branching, so the polymer chains cannot move past each other. It is this property that makes them hard, rigid, and brittle, and thus useful in crafting hard materials, such as the cross-linked rubber (styrene-butadiene rubber) that is used for most car and truck tires. The crosslinked polymer structure is why rubber car tires do not melt 
Figure 2

(A) Polymers can have three different structures: linear, branched, and cross-linked. (B) Structures of the monomers that form some common synthetic and natural polymers. Here, the straight lines represent bonds between atoms, and the different letters represent different these atoms ( $O$ is oxygen, $\mathrm{N}$ is Nitrogen, $\mathrm{H}$ is hydrogen, and no letter is usually a carbon atom) while $\mathrm{R}$ is any other atom or group of atoms, and $n$ is any number of repeating units in the polymer

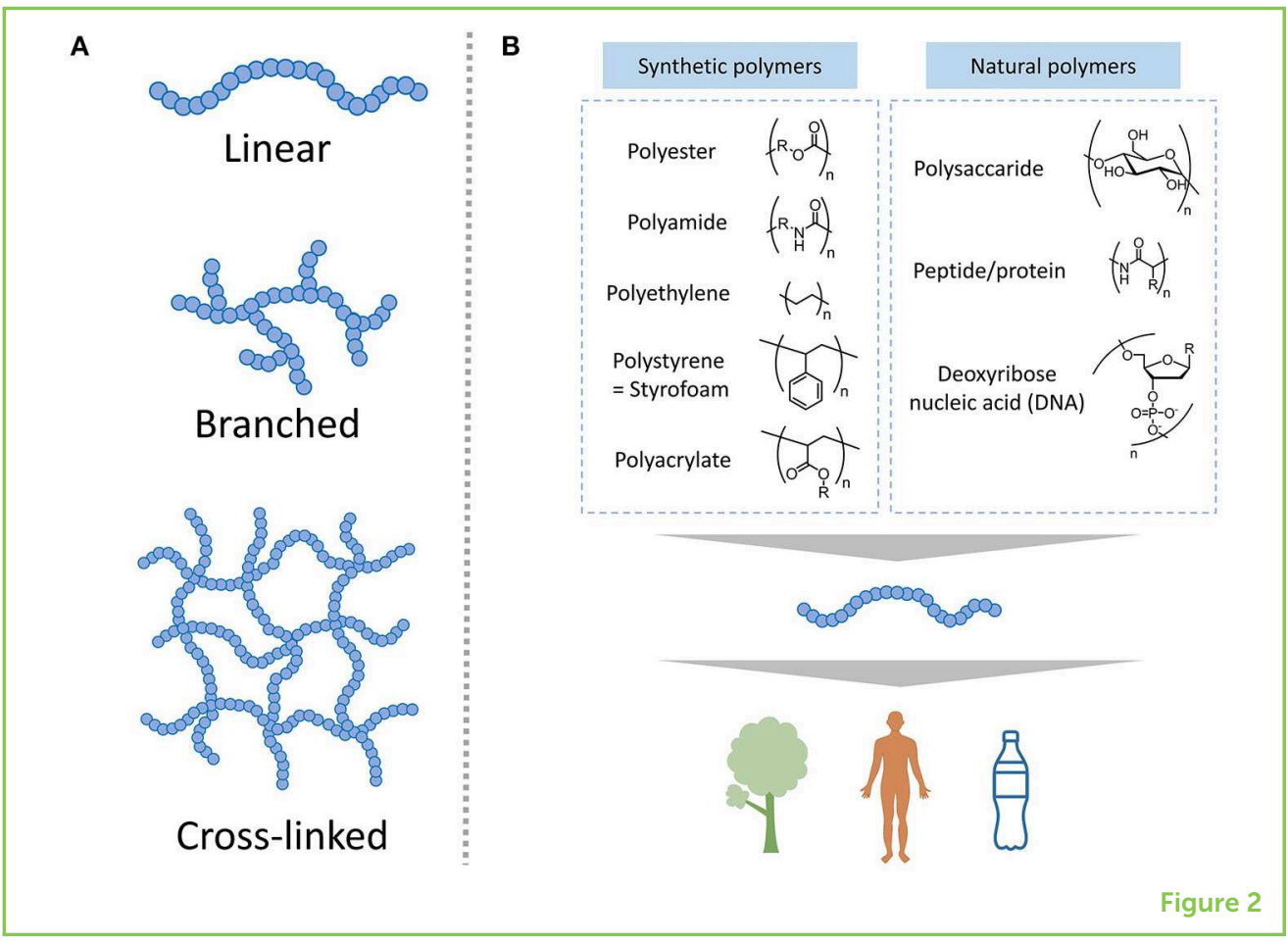

when you drive very fast, even though they get very hot from friction with the road.

Since we learned how to create and work with them, polymers, such as polyamide, polyester, and polyethylene have saturated our world. Polyamides are as strong as the bulletproof materials they are used for-like bulletproof vests. However, polyesters contain weaker bonds, and we use them to make things like biodegradable stitches for sewing up wounds. You can see some other polymer structures in Figure 2B, including some of the more complicated natural polymers made from sugars, amino acids, and nucleotides.

\section{WHY ARE MACROMOLECULES IMPORTANT FOR OUR HEALTH?}

Macromolecules have some pretty serious roles to play in the everyday functioning of our cells. For example, when synthetic polymers, which are used in implants for broken bones or in medicines, interact with our bodies, we need to make sure that they do not stay inside us for too long, because they can build up to toxic levels and become dangerous to body's health! So, these synthetic polymers are designed such that after they accomplish their tasks, they break down into smaller parts that our cells can naturally process. Due to their degradation within our bodies, we call these biodegradable polymers. One example of a class of biodegradable polymers are polyesters that are utilized in countless biomedical applications, such as dissolvable stiches, and also screws, plates, and pins, to support the repair of broken bones and hold them together. It is also important that synthetic polymers be compatible 
Figure 3

Polymers can help drugs to get into our bodies more efficiently. Drugs that are not easily soluble can be coated in polymers to make a tablet. The polymers help the drug to dissolve in the patient's body, so that when the patient takes the tablet the drug is not broken down in the stomach but is released at the correct pace into the blood stream.

\section{BIOCOMPATIBILITY}

The ability of a material to exist in the body without hurting the living tissue.

\section{SOLUBILITY}

The ability of a substance to mix into a liquid.

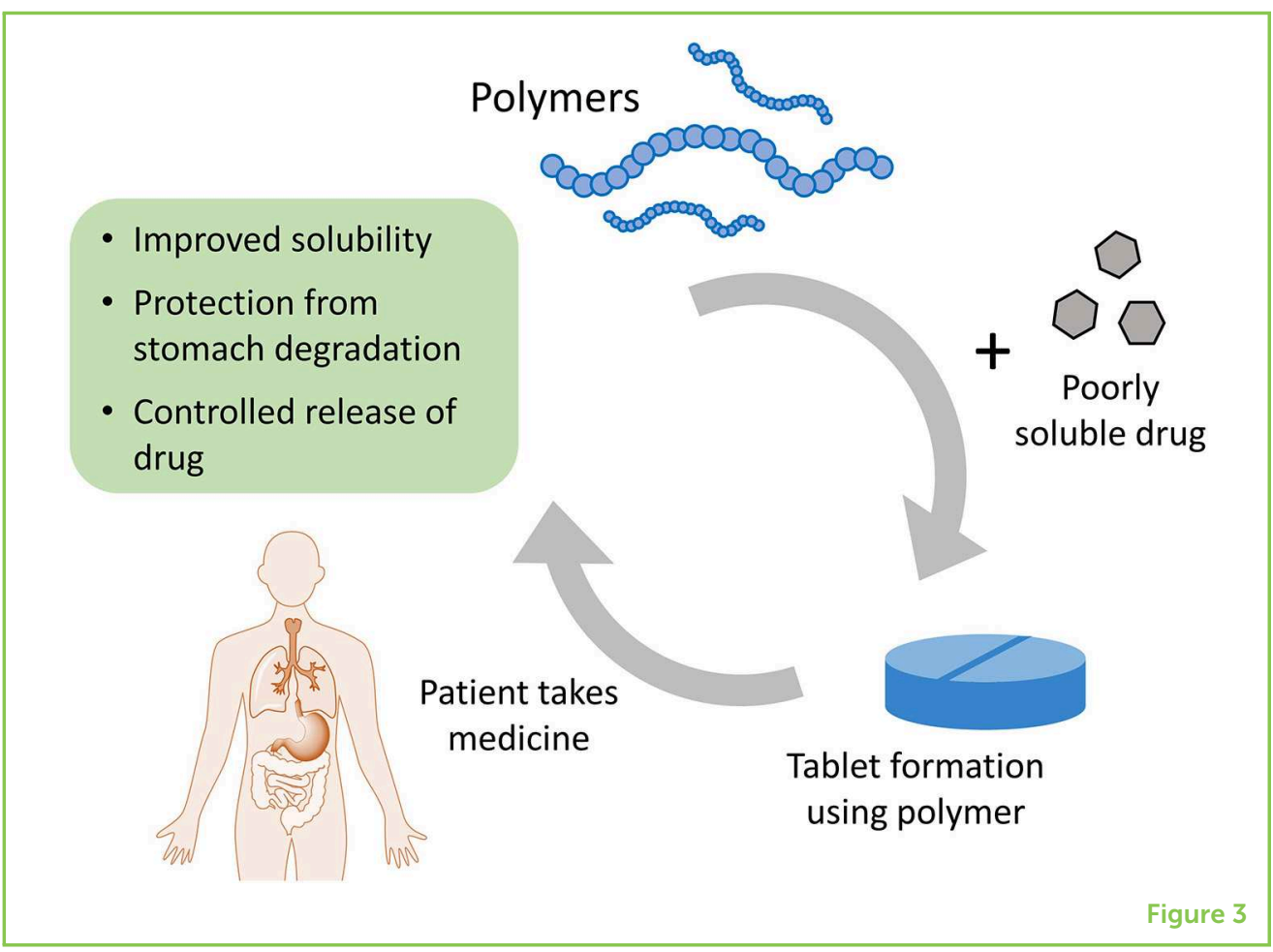

with our bodies, which is called biocompatibility. Biocompatibility allows the body to function normally in the presence of the polymer, without having any allergic reactions or adverse side effects from the polymer.

It is clear that the use of polymers has impacted our health, sometimes without us even knowing about it [3]. Here is an example. When we are sick, we usually have to swallow pills to help us get better more quickly. These pills generally dissolve in the stomach so that the medicine gets into the bloodstream. But, unfortunately, sometimes the drug is destroyed in the stomach or intestine before it gets into the blood stream and reaches the unhealthy organ. Or sometimes, the medicine does not have a chance to dissolve in the stomach. The job of the stomach is to dissolve things quickly, so making this process slower can be challenging. One solution? Make a pill with some specifically designed polymers!

For example, a medicine called nifedipine is used to treat high blood pressure, which is great news for almost 1 billion people suffering from this disease worldwide. However, the bad news is that nifedipine does not usually have enough time to dissolve in the stomach. Fortunately, a polymer comes to the rescue. A polymer called poly(vinylpyrrolidone) and is used to boost the ability of nifedipine to dissolve in the stomach. Scientists mix the low solubility nifedipine with the poly(vinylpyrrolidone) to form a tablet. By dressing nifedipine in a cloak made of this polymer, the drug is then able to safely reach the bloodstream (Figure 3) [4]. This is just one example of the many ways 
that macromolecules can have a positive impact on our health. So, the next secret to being healthy would not necessarily involve singing our hearts out to a popular Christmas song from the movie Love Actually, but might-actually-involve macromolecules.

\section{ACKNOWLEDGMENTS}

We would like to thank our mentors and advisors Dr. Paolo Decuzzi, Dr. Leanne Stokes, and Prof. Mark Searcey. This work was supported by the BBSRC Norwich Research Park Biosciences Doctoral Training Partnership (BB/M011216/1, 1794654) and the European Union's Horizon 2020 research and innovation program under the Marie Sklodowska-Curie grant agreement no. 754490.

\section{REFERENCES}

1. Mülhaupt, R. 2014. Hermann Staudinger and the origin of macromolecular chemistry. Angew. Chem. Int. Ed. Engl. 43:1054-63. doi: 10.1002/anie.200330070

2. Vandenberg, E. J. 2012. Contemporary Topics in Polymer Science. Vol. 5. New York, NY: Springer Science \& Business Media.

3. Langer, R., and Tirrell, D. A. 2004. Designing materials for biology and medicine. Nature 428:487. doi: 10.1038/nature02388

4. Marsac, P. J., Konno, H., and Taylor, L. S. 2006. A comparison of the physical stability of amorphous felodipine and nifedipine systems. Pharm. Res. 23:2306. doi: 10.1007/s11095-006-9047-9

SUBMITTED: 23 May 2019; ACCEPTED: 15 October 2019;

PUBLISHED ONLINE: 01 November 2019.

EDITED BY: Viduranga Y. Waisundara, Australian College of Business and Technology-Kandy Campus, Sri Lanka

CITATION: Cook AB and Bibic L (2019) Macromolecules, Actually: From Plastics to DNA. Front. Young Minds 7:126. doi: 10.3389/frym.2019.00126

CONFLICT OF INTEREST: The authors declare that the research was conducted in the absence of any commercial or financial relationships that could be construed as a potential conflict of interest.

COPYRIGHT @ 2019 Cook and Bibic. This is an open-access article distributed under the terms of the Creative Commons Attribution License (CC BY). The use, distribution or reproduction in other forums is permitted, provided the original author(s) and the copyright owner(s) are credited and that the original publication in this journal is cited, in accordance with accepted academic practice. No use, distribution or reproduction is permitted which does not comply with these terms. 



\section{YOUNG REVIEWERS}

\section{ANJISHNU, AGE: 12}

Hello, my name is Anjishnu and I am in the sixth grade. I live in San Diego and I have a passion for writing, reading, math and science. I also like reading about cars and other vehicles. I enjoy playing tennis and guitar. I want to be an aeronautical engineer when I grow up and would like to design planes that will make flying safer.

\section{JEANINE, AGE: 15}

I am a junior at a very competitive school which means that I always have to be prepared for what comes next. My favorite subjects are molecular biology and chemistry even though I also enjoy math and art history. Also, I enjoy swimming and being a member of the environmental club and track and field team. In addition, I make time to have lots of fun. My hobbies include reading fantasy books, watching documentaries, hanging out with my friends, and eating my favorite foods.

\section{AUTHORS}

\section{ALEXANDER B. COOK}

Alexander is a polymer chemist working in Italy as a Marie Sklodowska-Curie Cofund Fellow. He studied Chemistry at Imperial College and has a Ph.D. from the University of Warwick. In general, he is interested in applying materials science and engineering to help solve global problems. Currently, his research addresses new ways to treat various diseases, including neurological disorders. Having lived in the beautiful green countries of New Zealand, Italy, and the UK, he very much enjoys outdoor sports and mountains. *alexander.cookaiit.it

\section{LUCKA BIBIC}

Scientist by day, science writer ninja by night and spiderwoman somewhere in between: Lucka is wrapping up her Ph.D. at the University of East Anglia in the UK. Lucka's research interests have included making novel peptides for a variety of brain targets involved in cancer, neurodegenerative, and psychiatric disorders. Currently, Lucka is looking at the effects of spider venoms in chronic pain. When Lucka is not in the lab, she either runs, travels, or tweets at aluckabibic. *l.bibic @uea.ac.uk 